\title{
Cell-Type-Specific Modulation of Feedback Inhibition by Serotonin in the Hippocampus
}

\author{
Jochen Winterer, ${ }^{1}$ A. Vanessa Stempel, ${ }^{1}$ Tamar Dugladze, ${ }^{1,2}$ Csaba Földy, ${ }^{4}$ Nino Maziashvili, ${ }^{1,2}$ Aleksandar R. Zivkovic, ${ }^{1}$ \\ Josef Priller, ${ }^{3,6}$ Ivan Soltesz, ${ }^{4}$ Tengis Gloveli, ${ }^{1,2}$ and Dietmar Schmitz ${ }^{1,5,6,7}$ \\ ${ }^{1}$ Neuroscience Research Center, ${ }^{2}$ Institute of Neurophysiology, and ${ }^{3}$ Neuropsychiatry and Laboratory of Molecular Psychiatry, Campus Charité Mitte, \\ Charité-Universitätsmedizin Berlin, 10117 Berlin, Germany, ${ }^{4}$ Department of Anatomy and Neurobiology, University of California, Irvine, California 92697, \\ ${ }^{5}$ Bernstein Center for Computational Neuroscience Berlin, 10115 Berlin, Germany, ${ }^{6}$ Cluster of Excellence "NeuroCure," 10117 Berlin, Germany, and \\ ${ }^{7}$ Einstein Foundation Berlin, 10117 Berlin, Germany
}

Midbrain raphe nuclei provide strong serotonergic projections to the hippocampus, in which serotonin (5-HT) exerts differential effects mediated by multiple 5-HT receptor subtypes. The functional relevance of this diversity of information processing is poorly understood. Here we show that serotonin via $5-\mathrm{HT}_{1 \mathrm{~B}}$ heteroreceptors substantially reduces synaptic excitation of cholecystokinin-expressing interneurons in area CA1 of the rat hippocampus, in contrast to parvalbumin-expressing basket cells. The reduction is input specific, affecting only glutamatergic synaptic transmission originating from CA1 pyramidal cells. As a result, serotonin selectively decreases feedback inhibition via $5-\mathrm{HT}_{1 \mathrm{~B}}$ receptor activation and subsequently increases the integration time window for spike generation in $\mathrm{CA} 1$ pyramidal cells. Our data imply an important role for serotonergic modulation of GABAergic action in subcortical control of hippocampal output.

\section{Introduction}

Serotonin (5-HT) exerts numerous modulatory functions in the CNS in physiological conditions as well as in disease (Barnes and Sharp, 1999). Compounds regulating the reuptake or the metabolism of serotonin are commonly used as therapeutics in neuropsychiatric diseases such as depression, anxiety disorders, and many others (Duman et al., 1997; Ressler and Nemeroff, 2000; Krishnan and Nestler, 2008). A key role in regulating the release of serotonin is attributed to presynaptic serotonin $1 \mathrm{~A}\left(5-\mathrm{HT}_{1 \mathrm{~A}}\right)$ and serotonin $1 \mathrm{~B}\left(5-\mathrm{HT}_{1 \mathrm{~B}}\right)$ autoreceptors (Sari, 2004; Fink and Göthert, 2007). Recently, it has been demonstrated that the dynamic modulation of $5-\mathrm{HT}_{1 \mathrm{~B}}$ receptor function is an important adaptation mechanism downstream of 5-HT reuptake inhibition by antidepressants (Svenningsson et al., 2006). Despite evidence for involvement of $5-\mathrm{HT}_{1 \mathrm{~B}}$ receptor signaling in depression and other neuropsychiatric diseases, the precise role of the receptor in physiological conditions is unclear (Sari, 2004). A better understanding of the location and the function of the $5-\mathrm{HT}_{1 \mathrm{~B}}$ receptor

Received Dec. 8, 2010; revised March 18, 2011; accepted April 16, 2011

Author contributions: J.W., J.P., I.S., T.G., and D.S. designed research; J.W., A.V.S., T.D., C.F., N.M., and A.R.Z. performed research; J.W., A.V.S., and C.F. analyzed data; J.W., I.S., T.G., and D.S. wrote the paper.

This work was supported by Deutsche Forschungsgemeinschaft Grants Exc 257, SFB618, and SFB665 (D.S.) and SFBTR3/B5, GL254/5-1, and GRK1123 (T.G.), Bundesministerium für Bildung und Forschung (Bernstein Center for Computational Neuroscience Berlin, and Bernstein Focus: Neurotechnology Berlin) (D.S.), the Einstein Foundation Berlin (D.S.), and NIH Grant NS38580 (I.S.). We thank S. Walden, R. Zhu, and A. Schoenherr for technical assistance and $F$. Johenning for support with the uncaging experiments.

Correspondence should be addressed to Dietmar Schmitz, Neuroscience Research Center at the CharitéUniversitätsmedizin Berlin, Charitéplatz 1, 10117 Berlin, Germany. E-mail: dietmar.schmitz@charite.de.

C. Földy's present address: Department of Molecular and Cellular Physiology, Stanford University, Lorry Lokey Building, 265 Campus Drive, Stanford, CA 94305-5453.

DOI:10.1523/JNEUROSCI.6382-10.2011

Copyright $\odot 2011$ the authors $\quad 0270-6474 / 11 / 318464-12 \$ 15.00 / 0$ in cortical circuits is important to relate the receptors' mode of action to pathophysiological states.

GABAergic interneurons play a key role in the regulation of cortical networks, and serotonergic fibers from the raphe nuclei are known to project onto GABAergic interneurons in the hippocampus expressing the neuropetide cholecystokinin (CCK) and/or the calcium-binding protein calbindin (Freund et al., 1990; Cobb et al., 1995; McBain and Fisahn, 2001). Different classes of CCK-positive interneurons have been identified, and a major class of CCK-positive interneurons are basket cells, providing, together with parvalbumin (PV)-positive basket cells, the main proportion of perisomatic inhibition on pyramidal cells (Pawelzik et al., 2002). Because of their unique morphology, a key feature of perisomatic inhibitory cells is their ability to control the output and synchronize the action potential firing of their target cells (Miles et al., 1996). Recently, it has been suggested that perisomatic inhibitory cells display a functional dichotomy: whereas PV-positive basket cells provide a highly reliable clockwork that generates network oscillations, CCK-positive basket cells might serve as modulators that adapt network activity to behavioral states (Freund and Katona, 2007).

Here we show that serotonin activates presynaptic $5-\mathrm{HT}_{1 \mathrm{~B}}$ heteroreceptors in area CA1 of the hippocampus, thereby regulating glutamate release from excitatory inputs from CA1 pyramidal cells onto CCK-positive interneurons in a target-cellspecific manner, acting as a selective modulator of feedback inhibition in the hippocampus.

\section{Materials and Methods}

Ethics statement. Animal husbandry and experimental intervention was performed according to the German Animal Welfare Act and the European Council Directive 86/609/EEC regarding the protection of animals used for 
A

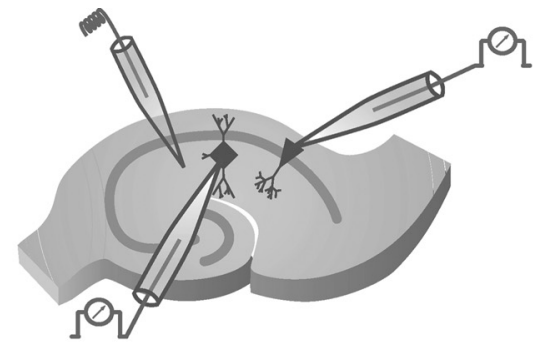

$A_{1}$
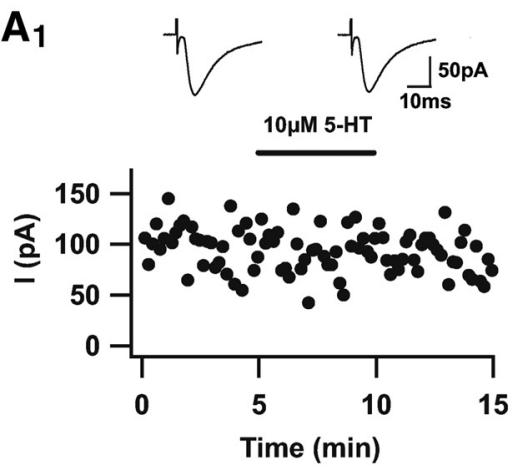

$\mathrm{A}_{2}$

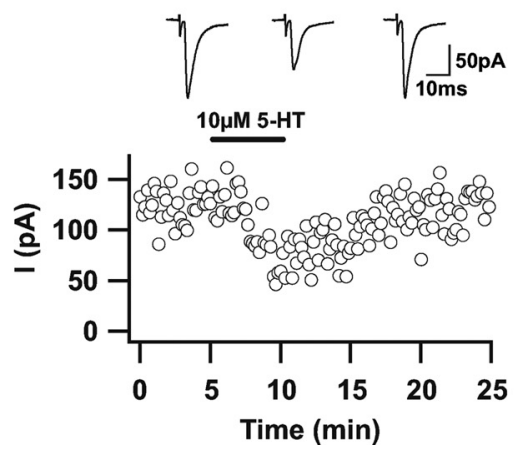

B
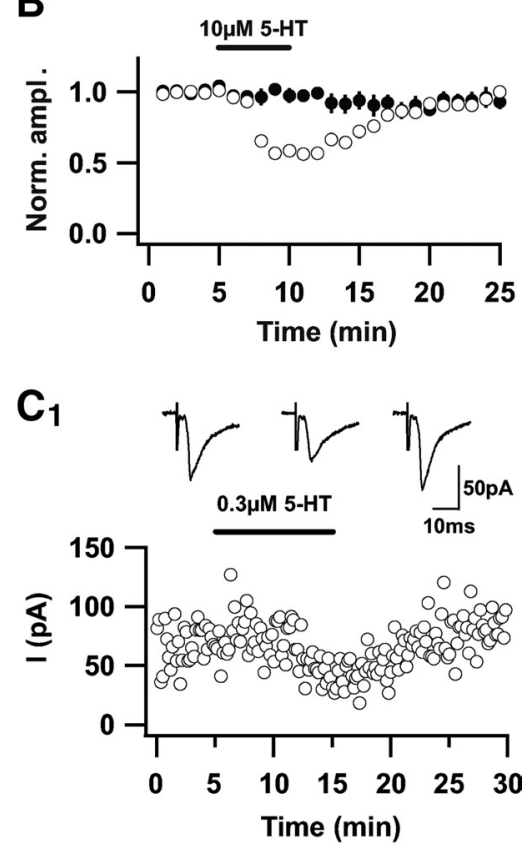

$\mathrm{C}_{2}$

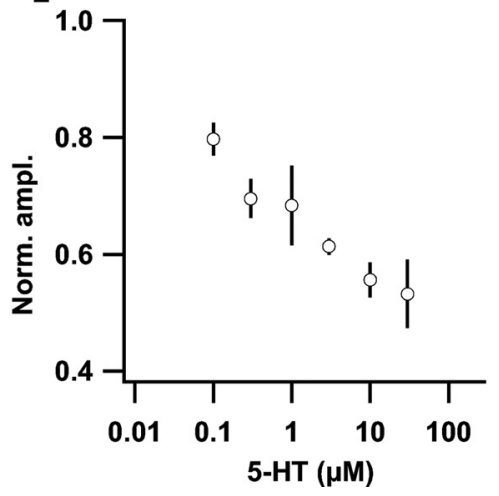

Figure 1. Distinct modulation of glutamatergic transmission onto pyramidal cells and interneurons by $5-\mathrm{HT}\left(V_{\text {holding }}=-60\right.$ $\mathrm{mV}$ ). $\boldsymbol{A}$, Schematic of the recording configuration (note that the single-cell recordings from the pyramidal cells and the interneurons were not done simultaneously in this set of experiments). $\boldsymbol{A}_{1}$, Top, Example traces of EPSCs in a CA1 pyramidal cell evoked by stimulation in stratum radiatum before and in $10 \mu \mathrm{m} 5-\mathrm{HT}$. Bottom, Time course of the measured EPSCs in the same cell. Calibration: $50 \mathrm{pA}, 10 \mathrm{~ms}$. $A_{2}$, Top, Example traces of EPSCs in an interneuron evoked by stimulation in stratum radiatum before, in $10 \mu \mathrm{m}$ 5-HT, and after washout. Bottom, Time course of the measured EPSCs in the same cell. Calibration: 50 pA, 10 ms. B, Summary of the time course of normalized and binned (1 min) EPSC amplitudes for pyramidal cell recordings (filled circles; $n=7$ ) and 5 -HTsensitive interneurons [open circles; $n=18$, selected from all 5 -HT-sensitive interneurons $(65.1 \%)$ of $n=86$ recorded interneurons]. Interneurons were included as serotonin sensitive if the reduction of the EPSC amplitude after application of $10 \mu \mathrm{M} 5$-HT was $\geq 30 \%$ of the baseline response and if this reduction was reversible. Black bar indicates the application of $10 \mu \mathrm{M} 5-\mathrm{HT} . \mathrm{C}_{1}, C_{2}$, Concentration dependency of 5 -HT effect onto interneurons. $C_{1}$, Top, Example traces of EPSCs in an interneuron evoked by stimulation in stratum radiatum before, in $0.3 \mu \mathrm{m} 5-\mathrm{HT}$, and after washout. Bottom, Time course of the measured EPSCs in the same cell. Black bar indicates application of $0.3 \mu \mathrm{m} 5$-HT. Calibration: $50 \mathrm{pA}, 10 \mathrm{~ms})$. $C_{2}$, Dose-response curve for 5 -HT concentrations. Normalized EPSC amplitudes are plotted against logarithmic scaled 5-HT concentrations $(0.1 \mu \mathrm{M}, n=3 ; 0.3 \mu \mathrm{M}, n=8 ; 1 \mu \mathrm{M}, n=$ $9 ; 3 \mu \mathrm{M}, n=2 ; 10 \mu \mathrm{M}, n=31 ;$ and $30 \mu \mathrm{m}, n=3$ ).

experimental and other scientific purposes. All animal maintenance and experiments were performed in accordance with the guidelines of local authorities (Berlin, Germany).

Preparation. Hippocampal slices were prepared from Wistar rats (P16-P24; both sexes) as described previously (Schmitz et al., 2003). In brief, the animals were anesthetized with isoflurane and decapitated, and the brains were removed. Tissue blocks containing the subicular area and hippocampus were mounted on a Vibratome (Leica VT1200) in a chamber filled with ice-cold artificial CSF (ACSF) containing the following (in mm): $87 \mathrm{NaCl}, 75$ sucrose, $26 \mathrm{NaHCO}_{3}, 2.5 \mathrm{KCl}, 1.25 \mathrm{NaH}_{2} \mathrm{PO}_{4}, 0.5$
$\mathrm{CaCl}_{2}, 7 \mathrm{MgSO}_{4}$, and 25 glucose, $\mathrm{pH} 7.4$ (saturated with $95 \% \mathrm{O}_{2}, 5 \% \mathrm{CO}_{2}$ ). Transverse slices were cut at $300-350 \mu \mathrm{m}$ thickness and were kept at $35^{\circ} \mathrm{C}$ for $30 \mathrm{~min}$. Slices were then cooled to room temperature and transferred to ACSF containing the following (in $\mathrm{mM}$ ): $119 \mathrm{NaCl}, 26$ $\mathrm{NaHCO}_{3}, 10$ glucose, $2.5 \mathrm{KCl}, 2.5 \mathrm{CaCl}_{2}, 1.3$ $\mathrm{MgCl}_{2}$, and $1 \mathrm{NaH}_{2} \mathrm{PO}_{4}$. All ACSF was equilibrated with $95 \% \mathrm{O}_{2}$ and $5 \% \mathrm{CO}_{2}$. The slices were stored in a submerged chamber, in which they were kept for 1-7 $\mathrm{h}$ before being transferred to the recording chamber. In the recording chamber, slices were perfused with ACSF at a rate of $3-4 \mathrm{ml} / \mathrm{min}$ at room temperature.

Electrophysiology. Whole-cell recording electrodes were filled with the following (in $\mathrm{mm}$ ): 135 K-gluconate, 10 HEPES, 2 Mg-ATP, 20 $\mathrm{KCl}, 0.2 \mathrm{EGTA}$, and 5 phosphocreatine. For EPSP-IPSP sequences, the following was used (in $\mathrm{mm}$ ): $150 \mathrm{~K}$-gluconate, 5 HEPES, 0.5 $\mathrm{MgCl}_{2}, 1.1$ EGTA 1.1 , and 10 phosphocreatine, with $\mathrm{pH}$ adjusted to 7.3 with $\mathrm{KOH}$. For staining and reconstruction of the recorded neurons, $0.2 \%$ biocytin was added to the intracellular solution. Excitatory postsynaptic responses were evoked by electrical stimulation (100 $\mu \mathrm{s}$ at $0.1 \mathrm{~Hz}$ ) in stratum radiatum of area CA1 via a broken patch pipette $(\sim 15 \mu \mathrm{m})$ filled with ACSF, in some experiments by alveus stimulation. Minimal stimulation was defined as follows: after establishing a synaptic input, the stimulus intensity was decreased until no synaptic response could be detected anymore, then the stimulus intensity was increased again slowly, until EPSCs of stable amplitudes and synaptic failures in an alternating manner appeared. For the minimal stimulation experiments, the average stimulation strength was $0.012 \pm 0.002 \mathrm{~mA}$. Experiments were done in the presence of the $\mathrm{GABA}_{\mathrm{A}}$ receptor-antagonist gabazine $(1 \mu \mathrm{M})$ and $100 \mathrm{nM}$ NBQX to prevent epileptiform activity and to minimize polysynaptic activity except when EPSP-IPSP sequences and monosynaptic IPSCs were measured. EPSPIPSP sequences were performed in the presence of $25 \mu \mathrm{M} \mathrm{D}-\mathrm{AP}-5$ and $10 \mu \mathrm{M}$ SCH50911 [(2S)(+)-5,5-Dimethyl-2-morpholineacetic acid], and monosynaptic IPSCs were performed in the presence of $25 \mu \mathrm{M}$ D-AP-5 and $10 \mu \mathrm{M}$ NBQX. Access resistances ranged between 9 and $28 \mathrm{M} \Omega$ for interneurons and between 6 and $20 \mathrm{M} \Omega$ for pyramidal cells. They were continuously monitored during the recording and were not allowed to vary $>25 \%$ during the course of the experiment. No series resistance compensation was used. Electrode resistances ranged from 2 to $5 \mathrm{M} \Omega$.

The intrinsic properties of cells were measured in whole-cell current-clamp mode. The resting membrane potential was estimated during the absence of a holding current, because recorded cells did not fire action potentials at rest. The input resistance was recorded in wholecell voltage-clamp mode. Only those recordings were included in the statistical analysis for input resistance measurements, in which the input resistance did not vary $>10 \%$ during the baseline recording before drug application.

Serotonin sensitivity of interneurons was determined by the reduction of the EPSC amplitude after application of $10 \mu \mathrm{m} 5-\mathrm{HT}$. If the reduction of the EPSC amplitude was $\geq 30 \%$ of the baseline response and if this 
Table 1. Characterization of interneuron subclasses

\begin{tabular}{|c|c|c|c|c|c|c|c|}
\hline & 5-HT sensitive (11) & & & 5-HT insensitive (30) & & & \\
\hline Spiking & Regular spiking (11) & & & Regular spiking (21) & & & Fast spiking (9) \\
\hline Immuno & CCK-positive (11) & & & CCK-positive (5) & & CCK-negative (16) & Parvalbumin-positive (4) \\
\hline Morphology & Basket (8) & Schaffer (2) & Failure (1) & Basket (4) & Failure (1) & Not further specified & Basket (7) \\
\hline
\end{tabular}

Immuno, Immunohistochemistry; Schaffer, Schaffer-collateral-associated interneuron; Failure, morphological reconstruction failed. $n$ values are shown in parentheses.

$A_{1 a}$
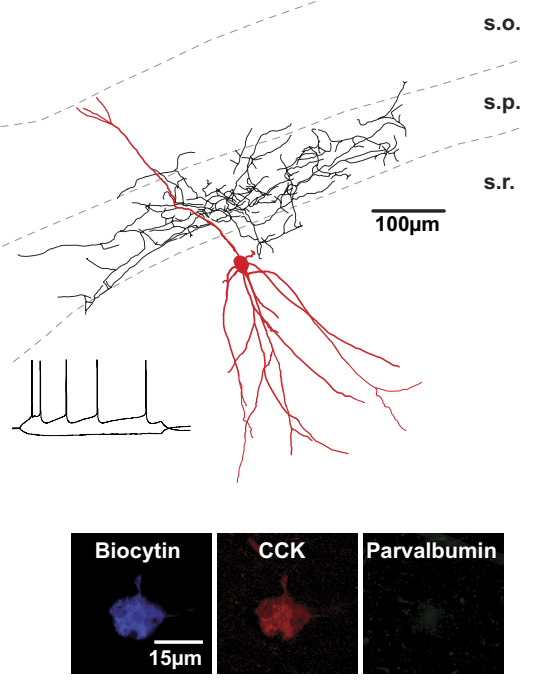

$A_{2 a}$<smiles>CCCCCCCC</smiles>

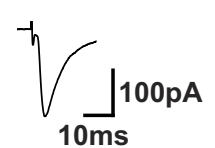

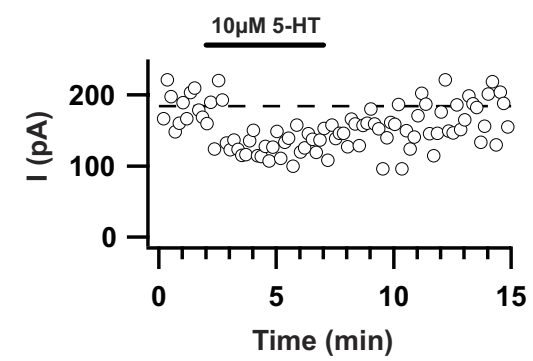

$\mathrm{A}_{3 a}$

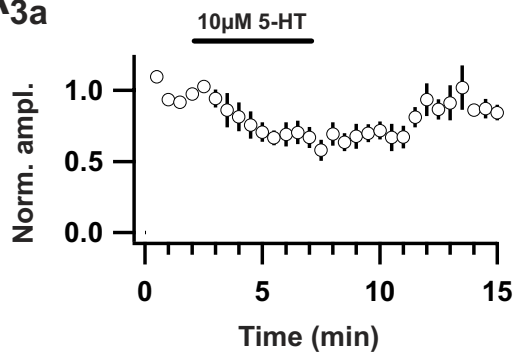

$A_{1 b}$
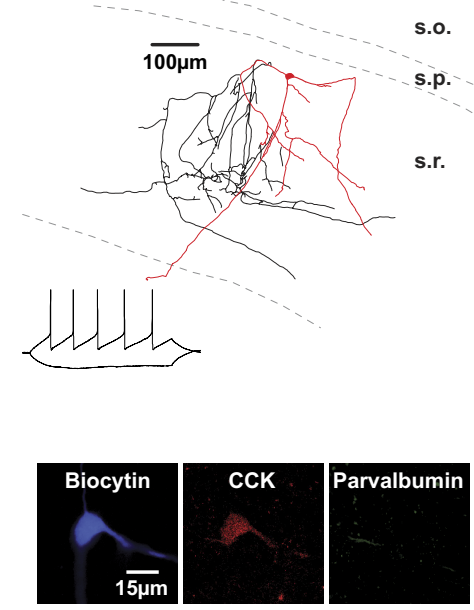

$A_{2 b}$
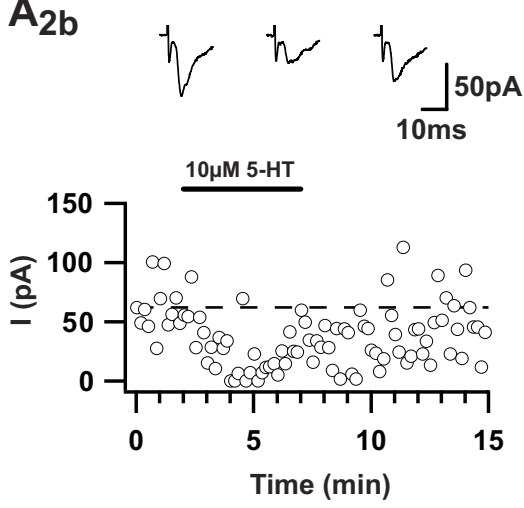

$A_{3 b}$

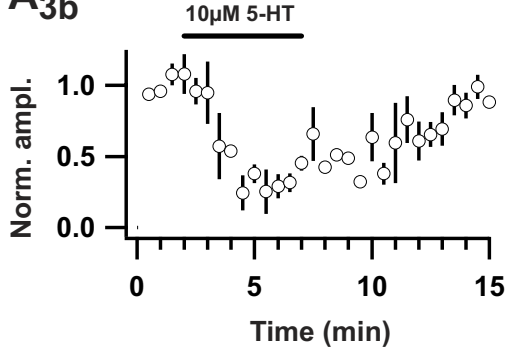

$B_{1}$
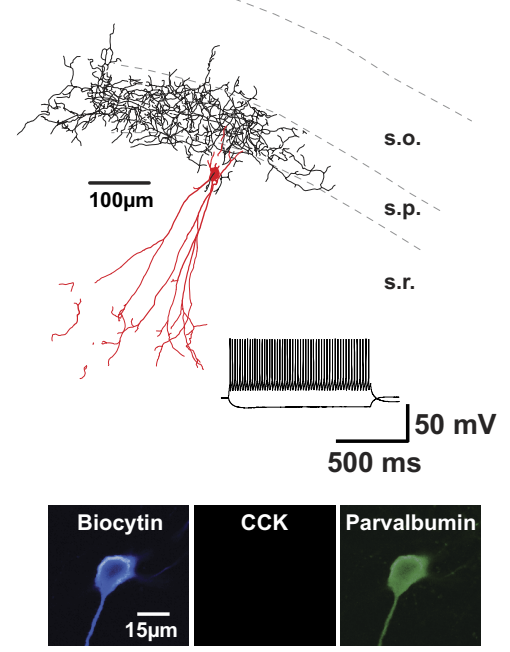

$B_{2}$

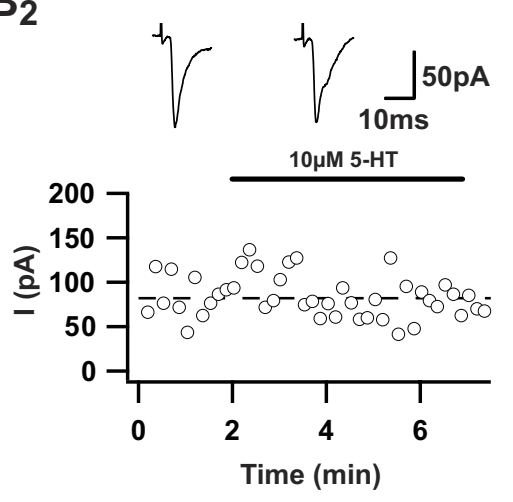

$\mathrm{B}_{3}$

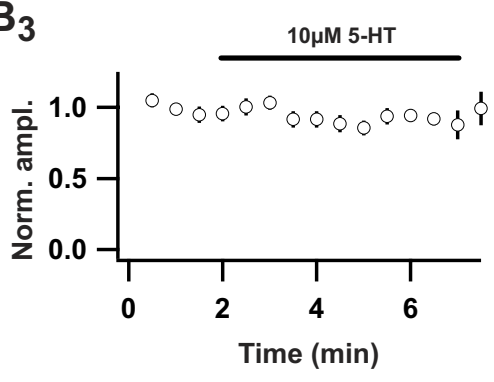

Figure 2. Characterization of morphological, immunohistochemical, and firing properties of serotonin-sensitive and serotonin-insensitive interneurons. Top, Reconstruction and spike pattern of a CCK-positive basket cell $\left(\boldsymbol{A}_{\boldsymbol{q}}\right)$, a CCK-positive Schaffer-collateral-associated interneuron $\left(\boldsymbol{A}_{\boldsymbol{l b}}\right)$, and a PV-positive basket cell $\left(\boldsymbol{B}_{\boldsymbol{1}}\right)$. Scale bars, $100 \mu \mathrm{m}$. Bottom, Immunohistochemistry of biocytin-filled CCK-positive cell body $\left(A_{1 a^{\prime}} A_{1 b}\right)$ and PV-positive cell body $\left(B_{1}\right)$ of the reconstructed interneurons. $A_{2 a^{\prime}}, A_{2 b}, B_{2}$, Top, Example traces of EPSCs of the characterized cells before, in $10 \mu \mathrm{m}$ 5-HT, and after washout. Bottom, Time courses of EPSCs in the same cells. $A_{3 a}$ Summary of the time course of normalized and binned ( $\left.0.5 \mathrm{~min}\right)$ EPSC amplitudes ( $n=8$ for CCK-positive basket cells). $\boldsymbol{A}_{\mathbf{3} \boldsymbol{b}}$, Summary of the time course of normalized and binned ( $\left.0.5 \mathrm{~min}\right)$ EPSC amplitudes ( $n=2 \mathrm{for}$ all CCK-positive Schaffer-collateral-associated interneurons). $\boldsymbol{B}_{3}$, Summary of the time course of normalized and binned ( $0.5 \mathrm{~min}$ ) EPSC amplitudes ( $n=9$ for fast-spiking interneurons, including 7 basket cells, of which 4 were PV positive; 1 fast-spiking interneuron showed PV-positive staining, but the axonal arborization was lost; 1 fast-spiking interneuron could not be reconstructed). Black bars indicate the application of $10 \mu$ m 5-HT. s.o., Stratum oriens; s.p., stratum pyramidale; s.r., stratum radiatum. 
A
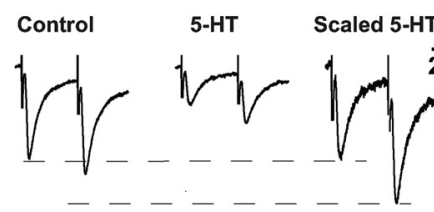

$---$

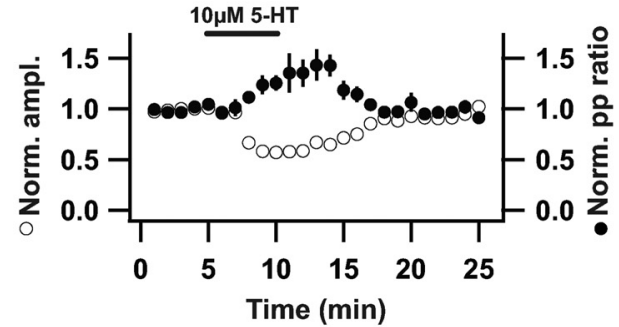

Time (min)

B
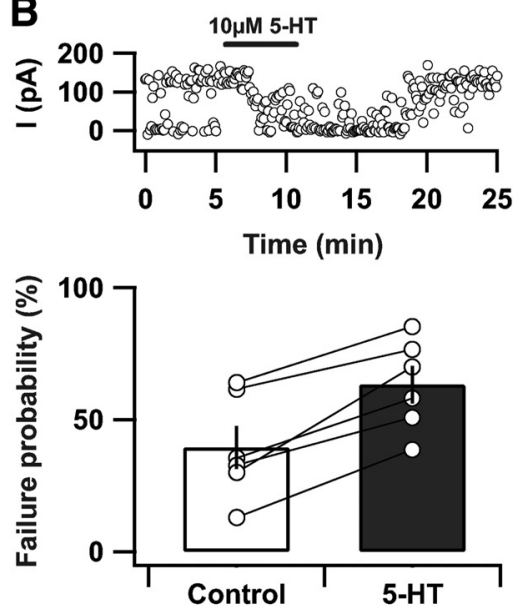

Figure 3. Presynaptic 5-HT receptors mediate the reduction of EPSC amplitudes. $\boldsymbol{A}$, Top, Example traces show pairedpulse (pp) facilitation (50 ms interstimulus interval) in control conditions, in $10 \mu \mathrm{m} 5-\mathrm{HT}$, and in $10 \mu \mathrm{m} 5$ - HT, scaled to the peak of first EPSC amplitude under control conditions. Calibration: $25 \mathrm{pA}, 25 \mathrm{~ms}$. Note the relative increase in the second EPSC amplitude in $10 \mu \mathrm{m} 5$-HT. Bottom, Summary of the time course of the normalized and binned (1 min) first EPSC (open circles) and of the normalized and binned ( $1 \mathrm{~min}$ ) paired-pulse ratio (filled circles; $n=16$ ). Black bar indicates application of $10 \mu \mathrm{m} 5$-HT. B, Top, Time course of a single experiment showing synaptic failures in control and in $10 \mu \mathrm{m} 5$-HT. Bottom, Summary graph of the probability of synaptic failures in control and in $10 \mu \mathrm{m} 5-\mathrm{HT}(n=6 ; p<0.05$, paired $t$ test). $C$, Coefficient of variation $(n=26)$. Filled circles indicate minimal stimulation experiments $(n=6)$. $\boldsymbol{D}$, Top, Example traces for stimulus-evoked EPSCs and glutamate-evoked currents under control conditions and in $10 \mu \mathrm{M} 5$-HT. Bottom, Summary $(n=5)$ of the time course of normalized and binned (1 $\mathrm{min})$ stimulus-evoked EPSCs (open circles) and glutamate-evoked currents (filled circles). Black bar indicates application of $10 \mu \mathrm{m} 5-\mathrm{HT}$.

reduction was reversible, interneurons were considered to be 5-HT sensitive. At lower concentrations ( 0.1 and $0.3 \mu \mathrm{M})$, a successive application of higher concentrations or, after washout of 5-HT, application of the 5- $\mathrm{HT}_{1 \mathrm{~B}}$ agonist defined the 5-HT sensitivity.

Average values in the text and the figures are expressed as means \pm SEM. The Student's $t$ test was used for statistical comparisons, and differences were considered statistically significant if $p<0.05$.

All example traces in the figures are averages of 10-30 sweeps unless otherwise stated. All points in the time course plots are individual EPSCs from individual recordings.

Drugs used included the following: 5- hydroxytryptamine creatine sulfate complex (5-HT) and fenfluramine (both from Sigma); NBQX, SR 95531 hydrobromide [6-Imino-3-(4-methoxyphenyl)-1(6H)-pyridazinebutanoic acid hydrobromide] (gabazine), D-AP-5, SCH50911 (selective GABA $_{\mathrm{B}}$ receptor antagonist), CP 93129 dihydrochloride [1,4-Dihydro-3-(1,2,3,6tetrahydro-4-pyridinyl)-5H-pyrrol [3,2-b]pyridin-5-one dihydrochloride] (selective $5-\mathrm{HT}_{1 \mathrm{~B}}$ receptor agonist), ( \pm )-7-Hydroxy-2-dipropylaminotetralin hydrobromide (8-OH-DPAT hydrobromide) (selective 5- $\mathrm{HT}_{1 \mathrm{~A} / 7}$ receptor agonist), GR127935 ( $N$-[4-methoxy-3-(4-methyl-1-piperazinyl) phenyl]-2'-methyl-4' -(5-methyl-1,2,4-oxadiazol-3-yl)-1-1'-biphenyl-4- carboxamide) (selective $5-\mathrm{HT}_{1 \mathrm{~B}}$ receptor antagonist), and 4-methoxy-7-nitroindolinyl (MNI)caged-L-glutamate (all from Tocris Bioscience). All drugs were bath applied.

Identification of interneurons. The identification of the CCK-positive interneurons and the PV-positive basket cells was based on morphology and immunohistochemistry (see below, Immunohistochemistry and neuroanatomy of interneurons). However, it is possible to selectively record from these distinct populations with a sufficient degree of confidence even before post hoc identification based on the position and shape of the cell body in stratum radiatum and pyramidale, the morphology of the dendrites visible by infrared differential interference contrast, and the electrophysiological characteristics in firing properties and input resistances (Földy et al., 2007; Neu et al., 2007). To characterize the discharge behavior of the cells, depolarizing current steps of 1000 ms duration were applied. Fast spiking interneurons displayed firing frequencies of $50-120.5 \mathrm{~Hz}$ at room temperature (mean firing frequency, $75.4 \pm 5.0 \mathrm{~Hz}$ ), whereas CCK-positive interneurons had a mean firing frequency of $11.1 \pm 1.0 \mathrm{~Hz}$. However, the maximum firing frequency also depends on temperature and on the amount of current injected. The mean input resistance of fast-spiking interneurons was $165.2 \pm 11.3$ $\mathrm{M} \Omega$, and the mean input resistance of CCKpositive interneurons was $302.8 \pm 17.6 \mathrm{M} \Omega$. CCK-positive interneurons were selected mainly in stratum radiatum and at the border of stratum radiatum/stratum pyramidale, and PV-positive interneurons were mainly selected at the border of stratum radiatum/stratum pyramidale and in stratum pyramidale.

Immunohistochemistry and neuroanatomy of interneurons. After recording, slices were transferred into a fixative solution containing $4 \%$ paraformaldehyde and $0.2 \%$ saturated picric acid in $0.1 \mathrm{M}$ phosphate buffer. Slices were resectioned into $70 \mu \mathrm{m}$ thin sections. Immunoreactivity for CCK was revealed with a mouse monoclonal antibody $[\mathrm{mAB}$ 9303, diluted 1:1000 in Tris-buffered saline containing $2 \%$ normal goat serum (TBSS); generously provided by the CURE Digestive Disease Research Center, Antibody RIA Core, Los Angeles, CA (NIH Grant DK41301)]; immunoreactivity for PV was tested with a rabbit polyclonal antibody (PV-28, diluted 1:1000 in TBSS; Swant) The reactions were visualized with a goat anti-rabbit IgG conjugated to Alexa Fluor 488 (diluted 1:500 in TBSS; Invitrogen) and a goat anti-mouse IgG conjugated to Alexa Fluor 594 (diluted 1:500 in TBSS) and streptavidin conjugated to Alexa Fluor 350 for biocytin (diluted 1:500 in TBSS). The sections were then mounted in Vectashield (Vector Laboratories) and analyzed with a fluorescence microscope. To reveal the presynaptic axonal arborization and dendritic arbors in detail, the biocytin-filled cells were subsequently visualized with 3,3'-diaminobenzidine tetrahydrochloride $(0.015 \%)$ using standard $\mathrm{ABC}$ kit (Vector Laboratories) and reconstructed with the aid of a Neurolucida 3D reconstruction system (MicroBrightField).

Glutamate uncaging. Twenty milliliters of $200 \mu \mathrm{M}$ MNI-caged-Lglutamate (Tocris Biosciences) were reperfused at $2.5-3.0 \mathrm{ml} / \mathrm{min}$. Uncaging was done using a UV-pulsed laser (Rapp Optoelektronik) attached with a $200 \mu \mathrm{m}$ optical fiber coupled into the epifluorescence port of the microscope with an OSI-BX adapter (Rapp Optoelektronik) and focused on the specimen by the objective lens. This yielded an illu- 
minated circle of $20-50 \mu \mathrm{m}$. The duration of the laser flash was $5 \mathrm{~ms}$. The laser power under the objective corresponding to the stimulus intensity levels used was monitored using a photo diode array-based photodetector (PDAK-60; Rapp Optoelectronics) and did not change over time. Glutamate was uncaged over the cell soma in the presence of the $\mathrm{GABA}_{\mathrm{A}}$ receptor antagonist gabazine $(1 \mu \mathrm{M})$ and 100 nM NBQX. For the experiments in which both somatic and synaptic currents were recorded, EPSCs were evoked with a stimulation electrode in stratum radiatum, thus evoking a synaptic response, and, after $500 \mathrm{~ms}$, a laser pulse was flashed to uncage MNI-glutamate, evoking a somatic current.

For the determination of the input specificity of the 5-HT effect, a grid of stimulation points with a raster size of $30 \mu \mathrm{m}$ was defined over areas CA3 and area CA1 of the hippocampus. After finding an input, repetitive uncaging was done at that specific location (for additional detail of the procedure, see Bendels et al., 2008). EPSCs elicited by photostimulation of single presynaptic neurons were Gaussian filtered and aligned to the peak of the response for subsequent averaging and quantification of the responses before and after application of CP93129.

\section{Results}

\section{Serotonin differentially modulates} excitatory transmission

We established whole-cell voltage-clamp recordings from pyramidal cells $(n=7)$, as well as different types of interneurons $(n=86)$ within area CA1 of the hippocampus and studied the role of 5-HT on glutamatergic transmission onto the different cell types. We found that stimulus-induced EPSCs, elicited by electrical stimulation in stratum radiatum, remained unaltered by 5 -HT when recorded from CA1 pyramidal neurons (Fig. $\left.1 A_{1}, B\right)$. Likewise, in a subset of interneurons $(34.9 \%)$ located in stratum radiatum of area CA1, stimulus-induced EPSCs were not affected by application of serotonin (see below). In sharp contrast, 5-HT effectively and reversibly inhibited glutamatergic transmission in a second subset of interneurons $(65.1 \%)$ within the same hippocampal area (Fig. $1 A_{2}, B$ ). Very low concentrations of 5-HT already had significant effects on excitatory inputs to these interneurons (Fig. $1 C_{1}$ ). The concentration dependence is shown in Figure $1 C_{2}$ (the concentration range was $0.1,0.3,1,3,10$, and 30 $\mu \mathrm{M})$. In some interneurons, $5-\mathrm{HT}$ application was paralleled by a decrease of the input resistance. Unlike the effects on excitatory inputs to interneurons, the decrease in input resistance could be observed reliably only at higher concentrations of 5-HT. We found a significant and reversible decrease in the input resistance at $10 \mu \mathrm{M}$ 5-HT (percentage of control in $10 \mu \mathrm{M}$ 5-HT: 77.3 \pm 5.6, $n=12, p<$ 0.05 , paired $t$ test; percentage of control after wash: $100.9 \pm 4.6, n=$ 12) (data not shown), whereas at concentrations of $0.3 \mu \mathrm{M} 5-\mathrm{HT}$, no significant decrease could be detected ( $p=0.18$, paired $t$ test) (data not shown).

\section{$A_{2}$}

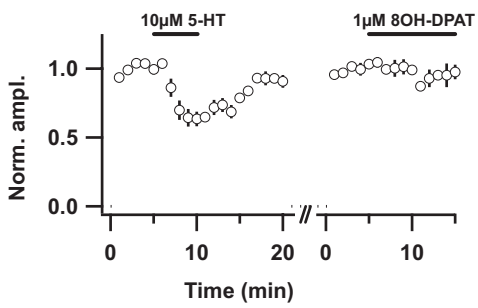

$\mathrm{B}_{2}$

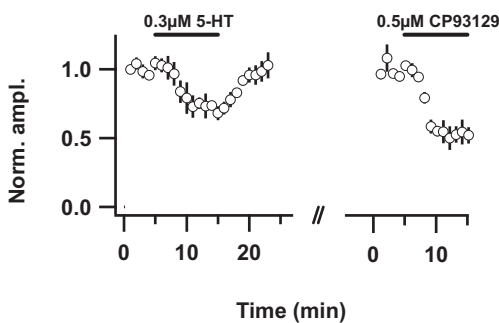

$\mathrm{C}_{2}$

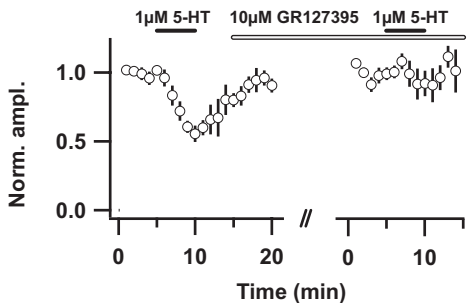

Figure 4. The reduction in glutamatergic transmission is mediated by $5-\mathrm{HT}_{1 \mathrm{~B}}$ receptors. $A_{1}$, Top, Example traces of EPSCs in control conditions, in $10 \mu \mathrm{m}$ 5-HT, and in $1 \mu \mathrm{m}$ 8-OH-DPAT. Bottom, Time course of EPSCs in the same cell. Black bars indicate the EPSC amplitudes $(n=6) \cdot \boldsymbol{B}_{1}$, Top, Example traces of EPSCs in control conditions, in $0.3 \mu \mathrm{m} 5-\mathrm{HT}$, after wash out, and in $0.5 \mu \mathrm{M}$ . traces of EPSCs in control, in $1 \mu \mathrm{m} 5$-HT, and in $10 \mu \mathrm{m}$ GR127395 and $1 \mu \mathrm{m}$ 5-HT. Bottom, Time course of EPSCs in the same cell. Black bars indicate the application of $1 \mu \mathrm{m} 5$-HT. The application of $10 \mu \mathrm{M}$ GR127395 is indicated as open bar. $C_{2}$, Summary of the time course of normalized and binned (1 min) EPSC amplitudes $(n=5)$.

These data indicate that 5 -HT is able to modulate excitatory inputs to interneurons and that this modulation is specific to a fraction of interneurons.

\section{Differential modulation of basket cell types by serotonin}

The observation that only a subset of interneurons responded to 5-HT application suggested a cell-type-specific modulation among different classes of interneurons. In the following set of experiments, we therefore further differentiated interneurons on the basis of their electrical properties, such as input resistance and firing properties, followed by immunohistochemical characterization and morphological reconstruction (Table 1) $(n=41)$. We found that 5-HT exclusively reduced the EPSC amplitude of CCK-positive interneurons, which had a high input resistance and slow firing frequency during depolarizing current injection (Fig. $\left.2 A_{3 b}\right)(n=11)$. Among these serotonin-sensitive cells (26.8\%), CCK-positive basket cells represented the biggest frac- 


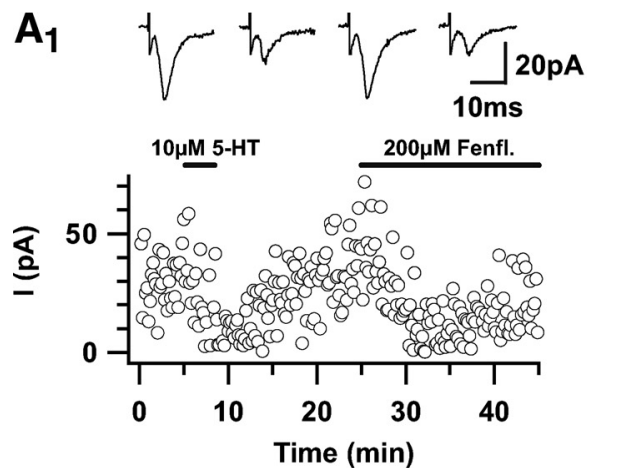

B
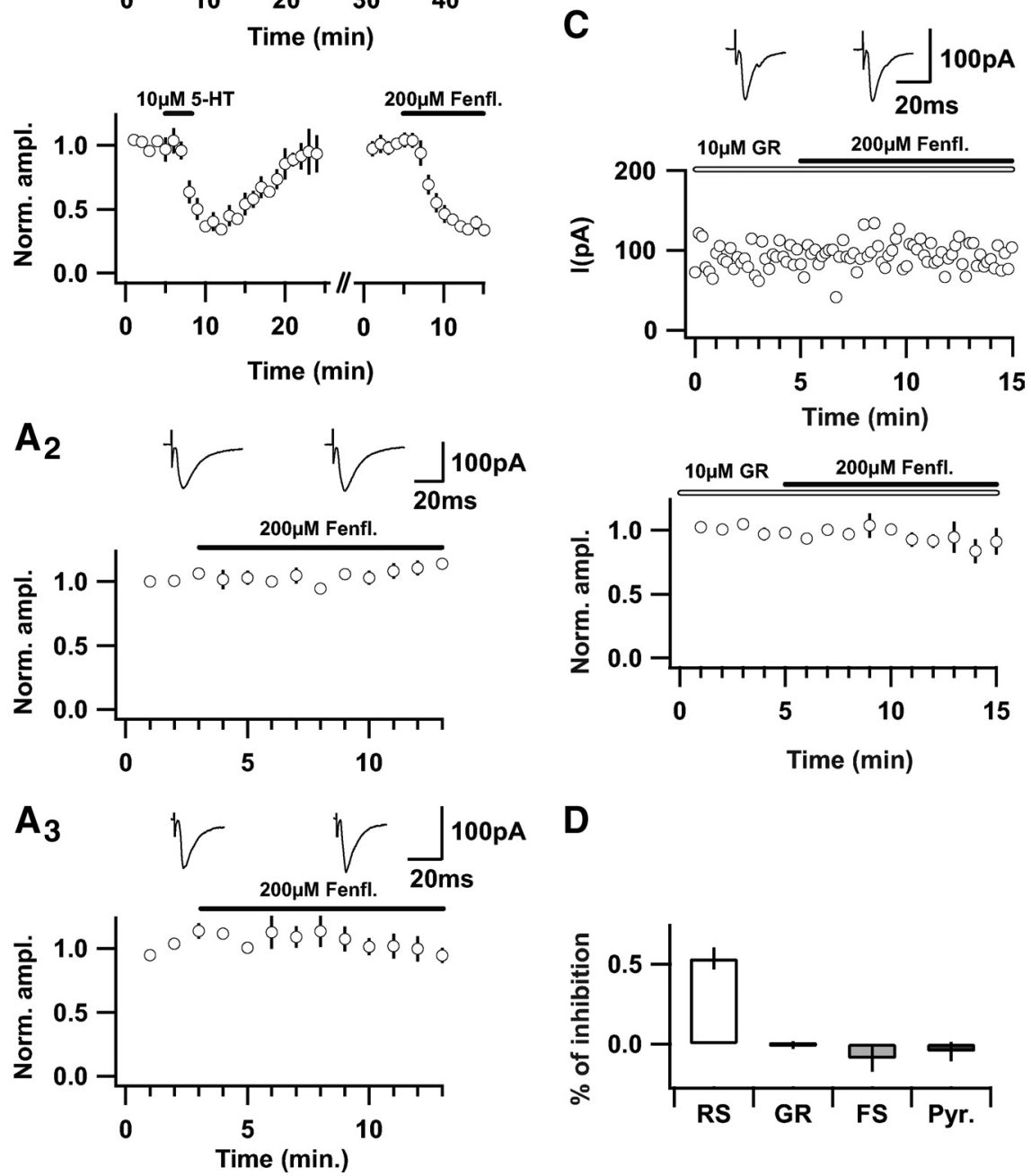

$100 \mathrm{pA}$

D

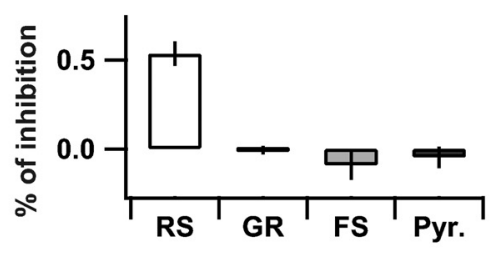

Figure 5. Fenfluramine mimics the effect of 5 -HT on interneurons. $A_{1}$, Top, Example traces of EPSCs in control conditions, in $10 \mu \mathrm{M}$ 5-HT, after washout, and in $200 \mu$ m fenfluramine (Fenfl.). Middle, Time course of EPSCs in the same cell. Black bars indicate the application of $10 \mu \mathrm{m} 5-\mathrm{HT}$ and the application of $200 \mu \mathrm{m}$ fenfluramine. Bottom, Summary of the time course of normalized and binned (1 min) EPSC amplitudes $(n=5)$. Fenfluramine has no effect on EPSCS in pyramidal cells $\left(A_{2}\right)$ and fast-spiking interneurons $\left(A_{3}\right) . A_{2}, A_{3}$, Top, Example traces of EPSC in control conditions and in $200 \mu \mathrm{m}$ fenfluramine. Bottom, Summary of the time course of normalized and binned (1 min) EPSC amplitudes in pyramidal cells $\left(\boldsymbol{A}_{2} ; n=5\right)$ and fast-spiking interneurons $\left(\boldsymbol{A}_{\boldsymbol{3}} ; n=5\right)$. $\boldsymbol{B}$, Paired-pulse ratio is increased from baseline: $1.00 \pm 0.03$ to $2.46 \pm 1.15$ in $10 \mu \mathrm{m} 5$-HT and after washout of 5 -HT from $1.11 \pm 0.10$ to $2.42 \pm 0.78$ in $200 \mu \mathrm{m}$ fenfluramine $(n=4)$. C, GR127935 antagonizes fenfluramine. Top, Example traces of EPSCs in $10 \mu \mathrm{m}$ GR127935 and in $10 \mu \mathrm{M}$ GR127935 and $200 \mu \mathrm{m}$ fenfluramine. Middle, Time course of EPSCs in the same cell. Bottom, Summary of the time course of normalized and binned (1 min) EPSC amplitudes $(n=5)$. Black bar indicates the application of $200 \mu$ m fenfluramine. $\boldsymbol{D}$, Summary graph of the percentage of inhibition of normalized EPSC amplitudes 5 min after application of fenfluramine in regular-spiking interneurons (RS), in regular-spiking interneurons with the antagonist GR127935 (GR), in fast-spiking interneurons (FS), and in CA1 pyramidal neurons (Pyr.).
CCK-positive and 5-HT-sensitive interneuron, the morphological reconstruction failed. We also found CCK-positive cells that were not sensitive to 5-HT application $(n=5)$ (see Discussion), of which four could be identified as basket cells and one could not be classified. In contrast to CCK-positive basket cells, CCK-negative interneurons with regular spike patterns $(n=16 ; 108.2 \pm 7.8 \%$ of control; $p=$ 0.31 ) (data not shown) and, in particular, interneurons with a lower input resistance and fast firing properties were never sensitive to 5-HT (Fig. $\left.2 B_{1}-B_{3}\right)(n=9$; $93.1 \pm 4.0 \%$ of control; $p=0.15$ ). Morphological reconstruction revealed that seven of nine fast-spiking interneurons could be classified as basket cells. Four were fully reconstructed and characterized as fast-spiking PV-positive basket cells. Unlike 5-HT-sensitive interneurons, the input resistance of fast-spiking interneurons was not affected by $5-\mathrm{HT}$ application (percentage of control in $10 \mu \mathrm{M}$ 5-HT: $90.7 \pm 6.3 ; n=5 ; p=0.22$ ) (data not shown). In summary, all interneurons that were sensitive to 5-HT application were CCK positive (see also Discussion), whereas fast-spiking PV-positive interneurons were never responsive.

\section{Serotonin mediates reduction of} excitation via a presynaptic mechanism The observed reduction of EPSC amplitudes by 5 -HT may be caused by a presynaptic reduction of transmitter release, a postsynaptic effect, or both. To discriminate between these scenarios, we performed the following sets of experiments on 5-HT-responsive cells. A presynaptic decrease in transmitter release probability will result in a reduced postsynaptic response but is also predicted to increase short-term facilitation (Zucker and Regehr, 2002). Typically, short-term plasticity is tested by synaptic stimulation with two closely timed pulses evoking pairedpulse facilitation or depression. Application of 5-HT led to an increase in the ratio of the second to first response from $1.58 \pm$ 0.19 to $2.17 \pm 0.29$ (Fig. $3 A)(n=16 ; p<$ 0.05 ), suggesting a presynaptic locus of serotonin action. A reduction in presynaptic transmitter release is additionally expected to result in a higher incidence of synaptic failures, i.e., presynaptic stimulation without successful synaptic transmission. Indeed, the probability of failures increased from $39.5 \pm 8.1 \%$ under contion (Fig. $\left.2 A_{1 a}-A_{3 a}\right)(n=8 ; 62.8 \pm 5.9 \%$ of control; $p<0.05)$. Another subclass of neurons that were sensitive to 5-HT could be identified as CCK-positive Schaffer-collateral-associated interneurons (Fig. $\left.2 A_{1 b}-A_{3 b}\right)(n=2 ; 0.45$ and $0.41 \%$ of control). For one trol conditions to $63.3 \pm 7.1 \%$ in the presence of 5 -HT (Fig. $3 B$ ) $(n=6 ; p<0.05)$. Based on the analysis of the coefficient of variation $(\mathrm{CV})$, a presynaptic locus of action is most likely as well, because the ratio $\mathrm{CV}^{2}$ control $/ \mathrm{CV}^{2}$ serotonin scaled linearly with the 
change of the mean response during application of 5- HT $(n=26)$ (Fig. 3C). Although the analysis of the coefficient of variation is commonly used to differentiate between presynaptic and postsynaptic mechanisms, this method is limited when using multiafferent stimulation (Faber and Korn, 1991). We therefore performed an additional set of experiments, in which we made use of the minimal stimulation technique and gained similar results (Fig. 3C, filled circles). To provide additional evidence for a presynaptic locus of action, we photolytically activated caged glutamate with a UV-laser flash. Figure $3 D$ shows experiments in which stimulus-evoked EPSCs and glutamate-evoked currents were measured in an alternating manner. Note that, although stimulus-evoked EPSCs were clearly reduced by 5 -HT, no such effect was found on glutamate-evoked currents. In summary, cumulative evidence indicates that serotonin decreases glutamatergic transmission through presynaptically localized 5-HT receptors.

\section{$5-\mathrm{HT}_{1 \mathrm{~B}}$ receptors mediate reduction in glutamatergic transmission}

To identify the subtype of 5-HT receptor mediating the depression of glutamatergic transmission, we tested various specific receptor agonists and antagonists. $5-\mathrm{HT}_{1 \mathrm{~A}}$ receptors are highly expressed in the hippocampus and mediate several effects of serotonin on intrinsic properties and synaptic potentials/currents of CA1 pyramidal neurons (Andrade and Nicoll, 1987; Colino and Halliwell, 1987; Schmitz et al., 1995). 8-OH-DPAT, a potent agonist at $5-\mathrm{HT}_{1 \mathrm{~A} / 7}$ receptors, however, did not mimic the presynaptic effects of serotonin on interneuron EPSCs. Importantly, within the very same cells, i.e., those treated with 8-OH-DPAT, serotonin clearly depressed glutamatergic transmission (Fig. $\left.4 A_{1}, A_{2}\right)$. Another subtype expressed in the hippocampal formation is the $5-\mathrm{HT}_{1 \mathrm{~B}}$ receptor, which has been shown to mediate effects of serotonin on synaptic potentials within area CA1 and the subiculum (Boeijinga and Boddeke, 1996; Mlinar et al., 2003). Indeed, we found that the $5-\mathrm{HT}_{1 \mathrm{~B}}$ receptor agonist CP93129 mimicked the effect of serotonin (Fig. $4 B_{1}, B_{2}$ ), yet, in contrast to high serotonin concentrations, CP93129 had no effect on the input resistance of the recorded interneurons (mean value in control, $251.2 \pm 44.5 \mathrm{M} \Omega$ vs mean value in $0.5 \mu \mathrm{M}$ CP93129, $244.9 \pm 38.1 \mathrm{M} \Omega ; n=4 ; p=0.75$, paired $t$ test) (data not shown). Moreover, GR127935, a potent and specific 5- $\mathrm{HT}_{1 \mathrm{~B}}$ receptor antagonist, blocked the effect of serotonin on interneuron EPSCs after subsequent 5-HT coapplication (Fig. $4 C_{1}, C_{2}$ ). In line with this finding, paired-pulse changes observed after the application of 5 -HT were also blocked by the $5-\mathrm{HT}_{1 \mathrm{~B}}$ receptor antagonist GR127935 (paired-pulse ratio in GR127935, $1.35 \pm 0.21$; in GR127935 and 5-HT, $1.44 \pm 0.27 ; n=5 ; p=0.39$, paired $t$ test) (data not shown). We conclude that the activation of $5-\mathrm{HT}_{1 \mathrm{~B}}$ receptors is most likely responsible for the effects of serotonin on glutamatergic transmission onto interneurons.

\section{Fenfluramine mimics the effect of bath-applied 5-HT}

Fenfluramine is thought to provoke the release of serotonin by disrupting the vesicular storage of 5-HT and consecutively reversing the serotonin transporter (Schmitz et al., 1999). Therefore, we tested whether the effect of serotonin on EPSCs could be mimicked by fenfluramine-induced physiological release of 5-HT from synaptic terminals. Having confirmed that the recorded interneuron was sensitive to 5 -HT, subsequent application of $200 \mu \mathrm{M}$ fenfluramine reliably mimicked the effect of 5 -HT (Fig. $5 A_{1}, D$ ). In contrast, excitatory inputs onto CA1 pyramidal
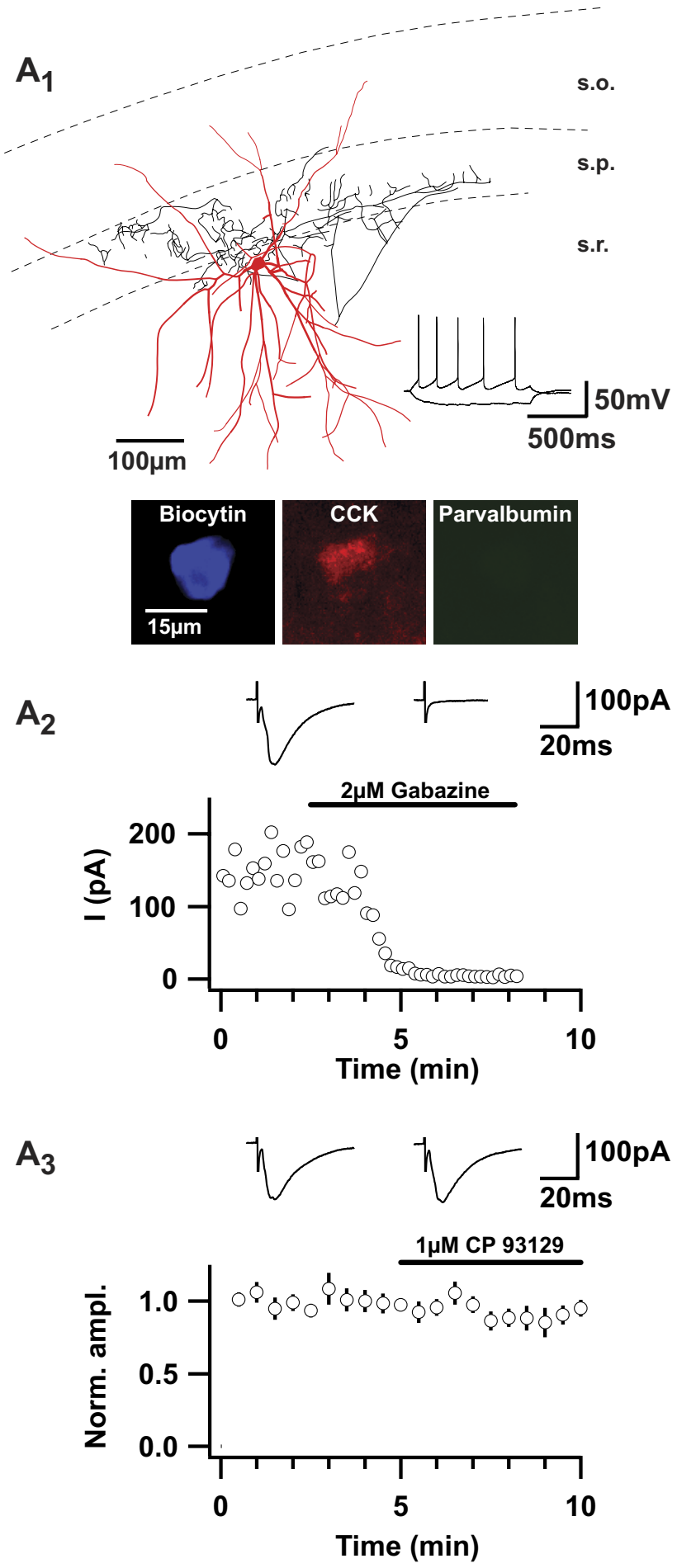

Figure 6. $5-\mathrm{HT}_{1 \mathrm{~B}}$ receptor signaling does not affect inhibition in CCK-positive interneurons. $A_{1}$, Top, Reconstruction and spike pattern of a CCK-positive basket cell. Bottom, Immunohistochemistry of biocytin-filled CCK-positive cell body of the reconstructed interneuron. $A_{2}$, Top, Example traces of stimulus-induced monosynaptic IPSCs before and after application of $2 \mu \mathrm{M}$ gabazine. Bottom, Time course of IPSCs in a CCK-positive basket cell; application of $2 \mu \mathrm{m}$ gabazine confirms the inhibitory input. $A_{3}$, Top, Example traces of stimulus-induced monosynaptic IPSCs before and after application of $1 \mu \mathrm{m}$ CP93129 of the characterized cell. Bottom, Summary of the time course of normalized and binned ( $0.5 \mathrm{~min})$ IPSC amplitudes $(n=6)$. Black bar indicates the application of $1 \mu \mathrm{M}$ CP93129. s.o., Stratum oriens; s.p., stratum pyramidale; s.r., stratum radiatum. 
A

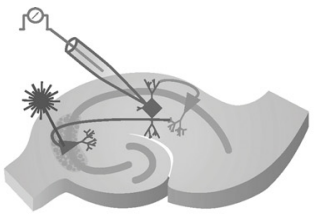

$A_{1}$
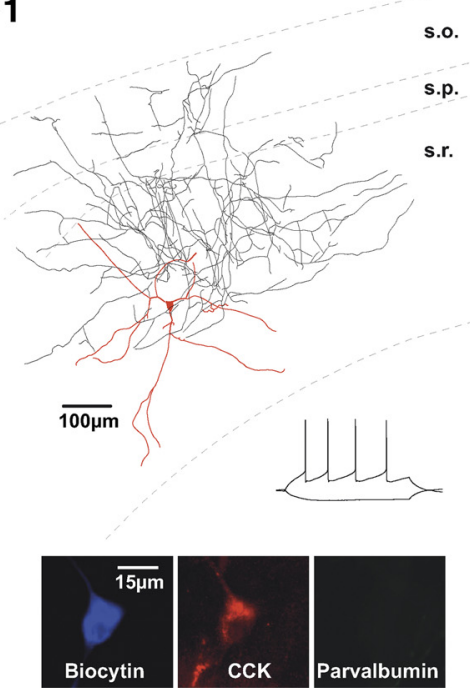

$A_{2}$
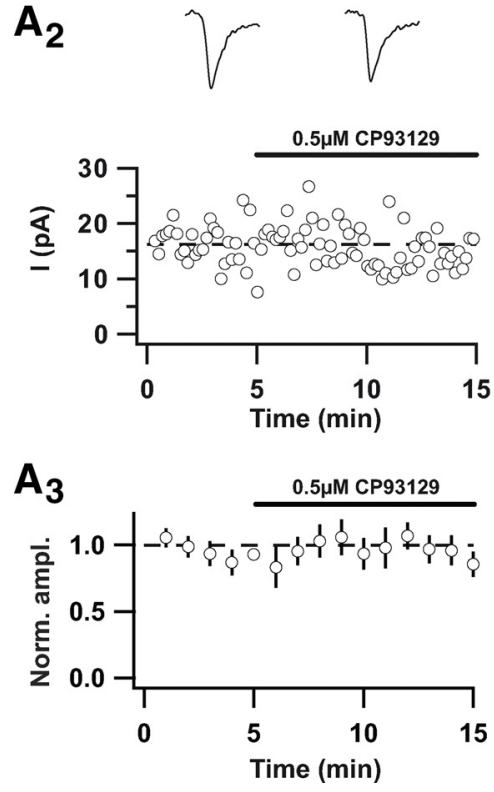

B

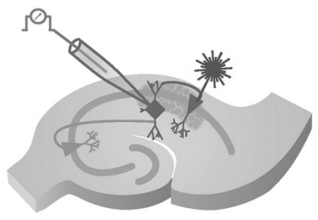

$B_{1}$
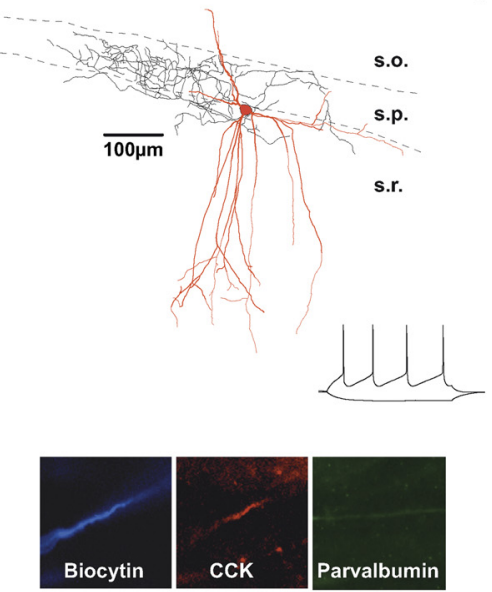

C

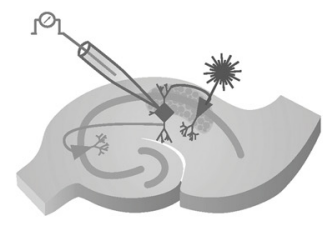

$\mathrm{C}_{1}$

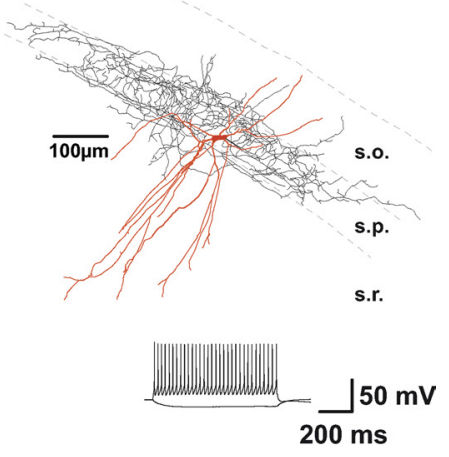

$\mathrm{C}_{2} \quad \nabla^{n} \nabla_{5 \mathrm{~ms}} 10 \mathrm{pA}$

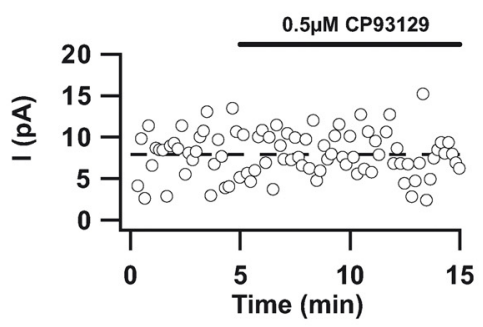

$\mathrm{C}_{3}$

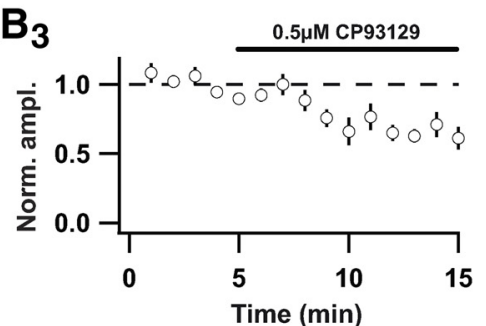

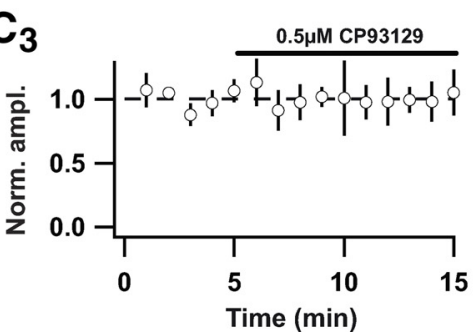

Figure 7. The depression of glutamate transmission by serotonin is input specific. $\boldsymbol{A}, \boldsymbol{B}, \boldsymbol{C}$, Schematic of the recording configuration. $\boldsymbol{A}_{1}, \boldsymbol{B}_{1}, \boldsymbol{C}_{1}$, Top, Reconstruction and spike pattern of a CCK-positive Schaffer-collateral-associated interneuron $\left(\boldsymbol{A}_{\boldsymbol{1}}\right)$, a CCK-positive basket cell $\left(\boldsymbol{B}_{\boldsymbol{1}}\right)$, and a fast-spiking basket cell $\left(\boldsymbol{C}_{\boldsymbol{1}}\right)$. Scale bars, $100 \mu \mathrm{m}$. Bottom, Immunohistochemistry of biocytin-filled CCK-positive cell body and dendrite $\left(\boldsymbol{A}_{1}, \boldsymbol{B}_{1}\right) \cdot \boldsymbol{A}_{2}, \boldsymbol{B}_{2}, \boldsymbol{C}_{2}$, Top, Example traces of EPSCs evoked by local uncaging of glutamate in area $C A 3\left(\boldsymbol{A}_{2}\right)$ and area CA1 $\left(\boldsymbol{B}_{2}, \boldsymbol{C}_{2}\right)$ before and in $0.5 \mu \mathrm{m} C P 93129$ of the characterized cells. Bottom, Time courses of EPSCs in the same cells. Summary of the time course of normalized and binned ( 1 min) EPSC amplitudes for CCK-positive interneurons $(n=6)$ evoked by local uncaging in $\mathrm{CA} 3\left(\boldsymbol{A}_{3}\right)$, for $C$ CK-positive interneurons $\left(\boldsymbol{B}_{3} ; n=9\right)$, and fast-spiking interneurons $(n=3)$ evoked by local uncaging in $C A 1\left(\boldsymbol{C}_{3}\right)$. s.o., Stratum oriens; s.p., stratum pyramidale; S.r., stratum radiatum.

neurons (Fig. $\left.5 A_{2}, D\right)$ as well as excitatory inputs onto fast-spiking interneurons were not affected (Fig. $\left.5 A_{3}, D\right)(n=5,4$ of which were basket cells, of which 2 were PV-positive, 1 could not be reconstructed). Corresponding to the changes in the paired-pulse ratio after bath application of 5-HT, fenfluramine increased the paired-pulse ratio from $1.10 \pm 0.10$ to $2.41 \pm 0.77$ (normalized EPSC amplitudes after washout of 5-HT; $n=4$ ) (Fig. 5B). Furthermore, the specific $5-\mathrm{HT}_{1 \mathrm{~B}}$ receptor antagonist GR127935 blocked the effect of endogenously released 5-HT on interneuron
EPSCs as well. After verifying that the recorded interneuron was sensitive to 5 -HT $(n=5$; percentage of control in $10 \mu \mathrm{M} 5-\mathrm{HT}$, $61.8 \pm 4.8 ; p<0.05$ ) (data not shown), application of fenfluramine did not affect EPSC amplitudes significantly during coapplication of GR127935 (Fig. 5C,D) $(n=5$; percentage of control in $200 \mu \mathrm{M}$ fenfluramine, $87.5 \pm 9.4 ; p=0.24$, paired $t$ test). These data indicate that endogenous release of 5-HT as well is able to modulate excitatory inputs onto interneurons in a celltype-specific manner. 
Input-specific modulation by

$5-\mathrm{HT}_{1 \mathrm{~B}}$ receptors

In situ hybridization revealed that, in the cortex, the highest expression levels of $5-\mathrm{HT}_{1 \mathrm{~B}}$ receptor mRNA can be detected in the pyramidal cell layer of area CA1 of the hippocampus, whereas there is no detectable expression in CA3 pyramidal cells and dentate gyrus granule cells (Voigt et al., 1991; Svenningsson et al., 2006). This prompted us to test the hypotheses that, first, serotonergic modulation by $5-\mathrm{HT}_{1 \mathrm{~B}}$ receptor signaling is restricted to glutamatergic transmission and, second, that this modulation of glutamatergic transmission is input specific.

According to the pattern of $5-\mathrm{HT}_{1 \mathrm{~B}}$ receptor mRNA expression, 5-HT had no effect on stimulus-induced monosynaptic IPSCs onto CCK-positive interneurons. (Fig. $\left.6 A_{3}\right)(n=6$; percentage of control in $1 \mu \mathrm{M}$ CP93129, $92.0 \pm 7.1 ; p=0.38$, paired $t$ test). To probe the input specificity, we aimed to differentiate between CA3 and CA1 inputs onto interneurons by focal release of caged glutamate with a UV-laser flash, in the pyramidal cell layer of either area CA3 or area CA1 of the hippocampus. Because 5 -HT is known to modulate the intrinsic properties of hippocampal pyramidal cells via $5-\mathrm{HT}_{1 \mathrm{~A}}$ receptors (Andrade and Nicoll, 1987; Colino and Halliwell, 1987) and 5- $\mathrm{HT}_{4}$ receptors (Torres et al., 1995, 1996), we made use of the $5-\mathrm{HT}_{1 \mathrm{~B}}$ receptor agonist CP93129 instead of 5-HT to ensure that the intrinsic properties of the stimulated pyramidal cells remained unaffected. We observed that CP93129 had no effect on EPSCs onto CCK-positive interneurons, if the excitatory input originated from a CA3 pyramidal cell (mean inhibition, $5.3 \pm 8.7 \%$; $p=0.79$, paired $t$ test; $n=6$, including 2 basket cells and 2 Schaffer-collateralassociated cells and 2 cells that could not be reconstructed) (Fig. $7 A_{1}-A_{3}$ ). If, in contrast, the excitatory input derived from CA1 pyramidal cells, then the EPSCs were depressed (mean inhibition, $35.6 \pm 5.9 \%$; $p<0.05$, paired $t$ test; $n=9$, including 4 basket cells, 3 Schaffer-collateralassociated cells, and 2 cells that could not be reconstructed) (Fig. $7 B_{1}-B_{3}$ ). Additionally, we tested whether fast-spiking basket cells were sensitive to the $5-\mathrm{HT}_{1 \mathrm{~B}}$ receptor agonist CP93129 when the excitatory input arose from CA1 pyramidal cell firing. Again, we did not detect a decrease in EPSC amplitude of fast-spiking basket cells (mean inhibition, $-2.5 \pm 11.5 \% ; p=0.85$, paired $t$ test; $n=3$ ) (Fig. $\left.7 C_{1}-C_{3}\right)$.

\section{Serotonin reduces feedback inhibition in area CA1 of the hippocampus}

To assess the functional role of the observed reduction of EPSC amplitudes in CCK-positive interneurons by 5-HT, we asked

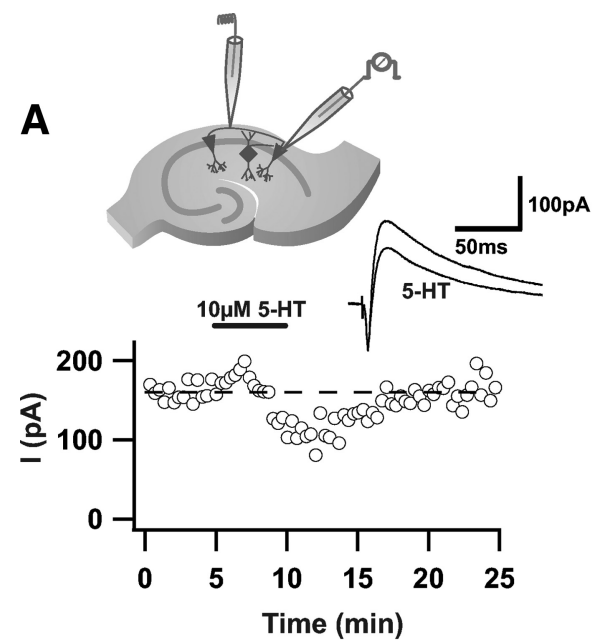

B
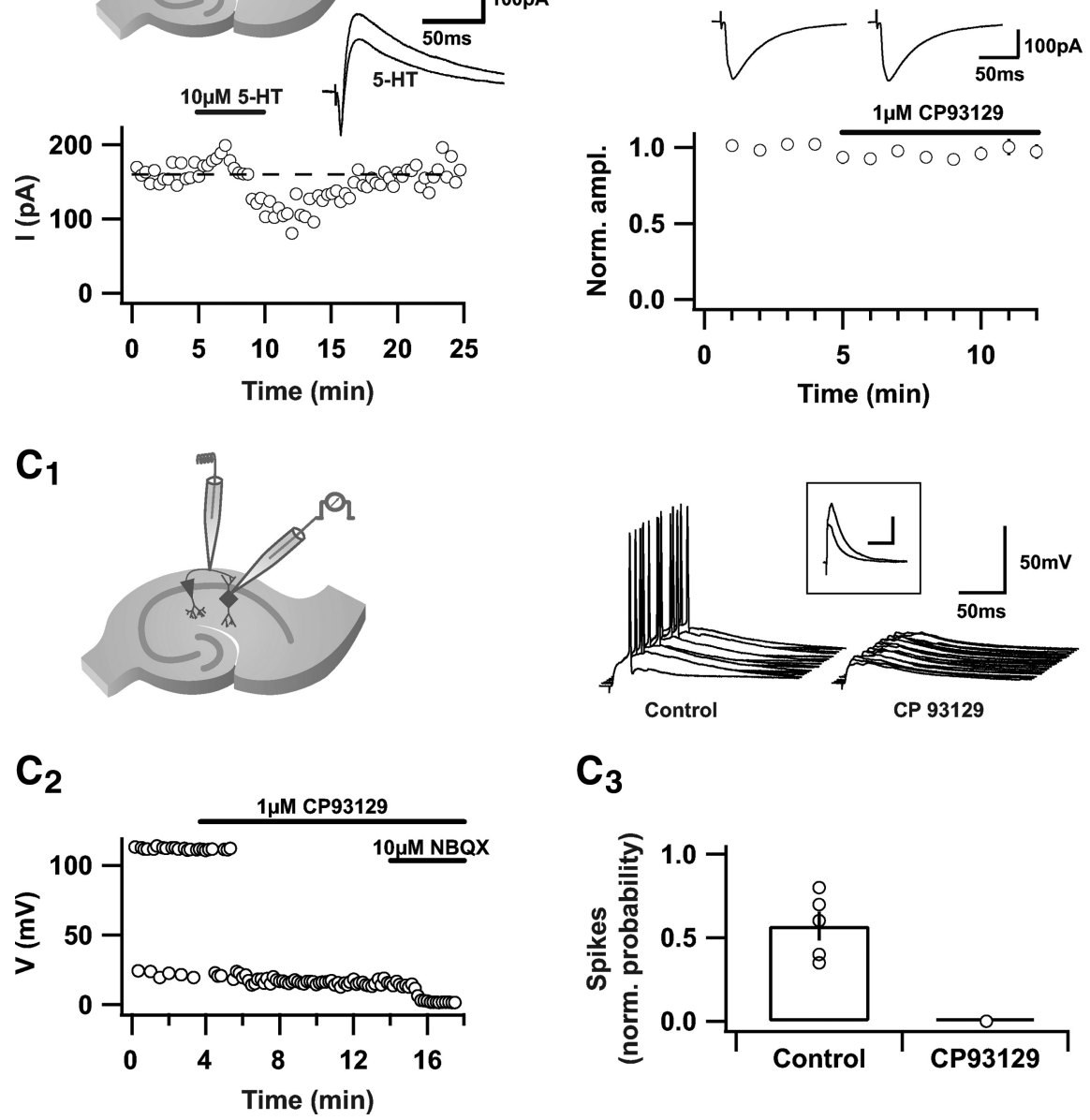

$\mathrm{C}_{3}$

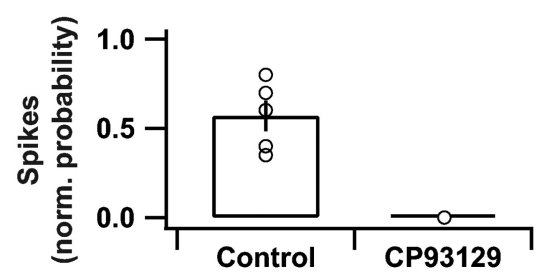

Figure 8. 5-HT reduces feedback inhibition in CA1 pyramidal cells. $A$, Top, Schematic of the recording configuration. Bottom, Time course of IPSCs in an example cell. Black bars indicate the application of $10 \mu \mathrm{m}$ 5-HT. Inset, Example traces of EPSC-IPSC sequences stimulated in the alveus in control conditions and in $10 \mu \mathrm{m} 5$-HT. Calibration: $100 \mathrm{pA}, 50 \mathrm{~ms}$. B, Top, Example traces of

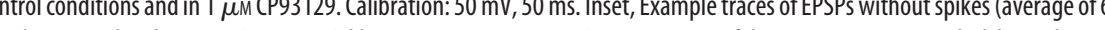
the application of $1 \mu \mathrm{M}$ CP93129 and $10 \mu \mathrm{M}$ NBQX. $C_{3}$, Summary graph of the normalized spike probability in control conditions and in $1 \mu \mathrm{M}$ CP93129 ( $n=5,4$ interneurons could be reconstructed as regular spiking basket cells, of which 3 were CCK positive, 1 reconstruction failed; spike probability in control conditions, $57.0 \pm 0.09 \mathrm{vs} 0 \%$ in (P93129; $p<0.05$, paired $t$ test;).

whether 5-HT is able to reduce inhibition in CA1 pyramidal cells. We recorded EPSC-IPSC sequences in CA1 pyramidal cells, elicited by electrical stimulation in the alveus, in which activation of CA1 pyramidal cell axons is most likely. Indeed, a significant reduction of the IPSC component to $70.9 \pm 3 \%$ after application of $10 \mu \mathrm{M}$ 5-HT (Fig. $8 A$ ) could be observed, whereas the EPSC component was not significantly altered (data not shown). The reduction of the IPSC component might result from a direct activation of $5-\mathrm{HT}_{1 \mathrm{~B}}$ receptors on inhibitory synapses. To rule out this scenario, we measured monosynaptic IPSCs in CA1 pyramidal cells, elicited by electrical stimulation in stratum radiatum (in the presence of NBQX and D-AP-5). However, we could not detect any effect of the $5-\mathrm{HT}_{1 \mathrm{~B}}$ receptor agonist CP93129 on stimulus-induced IPSCs (Fig. $8 \mathrm{~B}$ ). 
Because disynaptic inhibition is reduced in CA1 pyramidal cells during alveus stimulation, we hypothesized that activation of presynaptic $5-\mathrm{HT}_{1 \mathrm{~B}}$ receptors is sufficient to reduce spike probability in serotonin-sensitive interneurons. To address this, we recorded from serotonin-sensitive interneurons, stimulated in the alveus, and set the stimulation at an intensity generating a spike in $\sim 60 \%$ of the stimuli in the recorded interneuron. After application of the 5- $\mathrm{HT}_{1 \mathrm{~B}}$ receptor agonist CP93129, the spike probability was decreased to zero in all of the recorded interneurons (Fig. $\left.8 C_{1}-C_{3}\right)(n=5$; spike probability, $57.0 \pm 0.09 \%$ under control vs 0\% in CP93129; $p<0.05$; four interneurons could be characterized and reconstructed as regular spiking basket cells, of which three were CCK positive, and one reconstruction failed). In agreement with this finding, the comparison of EPSPs without spikes in control and in CP93129 revealed a significant reduction in EPSP amplitude after drug application of CP93129 (Fig. $8 C_{1}$, inset) $(n=5$; EPSP amplitude in CP93129, $66.6 \pm 7 \%$ of control; $p<0.05)$ (data not shown).

\section{Serotonin broadens the integration time window for spike timing}

CCK-positive basket cells preferentially participate in feedback inhibition as a result of their ability to integrate independent inputs over a broad time window (Glickfeld and Scanziani, 2006). Because the probability of spike generation in serotonin-sensitive interneurons is dramatically reduced and consequently feedback inhibition is substantially affected by $5-\mathrm{HT}$ and by the $5-\mathrm{HT}_{1 \mathrm{~B}}$ receptor agonist CP93129, we tested whether serotonin can influence spike timing of CA1 pyramidal cells via modulation of CCK-positive basket cell recruitment.

We stimulated two independent pathways (alveus and Schaffer-collateral pathway) and measured the evoked EPSPIPSP sequences in a CA1 pyramidal cell in current-clamp mode. To determine the integration time window for spike generation, we set the stimulus intensity of the alveus and the Schaffercollateral pathway at the threshold for spike generation, when the two pathways were stimulated simultaneously. By delaying the Schaffer-collateral stimulation with respect to the alveus stimulation, the probability of generating a spike at different interstimulus intervals was determined. Indeed, we observed a broadening of the integration time window for spike generation in CA1 pyramidal cells by application of the $5-\mathrm{HT}_{1 \mathrm{~B}}$ receptor agonist CP93129 (Fig. 9). At 5 and $10 \mathrm{~ms}$ interstimulus intervals, CP93129 increased the probability of spike generation from $16 \pm$ 5.1 and $0 \%$ (under control conditions) to $70 \pm 11.4$ and $34 \pm$ $9.8 \%$, respectively, thereby demonstrating an effective expansion of the integration time window by $5-\mathrm{HT}_{1 \mathrm{~B}}$ receptor activation (Fig. 9C) $(n=5)$.

\section{Discussion}

Here, we describe a new and highly specific form of neuromodulation within the hippocampal area CA1 by serotonin. It has been shown that raphe-hippocampal fibers are innervating and exciting specific GABAergic interneurons in the hippocampus by serotonin via ionotropic $5-\mathrm{HT}_{3}$ receptors (McMahon and Kauer, 1997). In the present study, we show that serotonin efficiently reduces glutamate release from hippocampal CA1 pyramidal cells onto CCK-positive interneurons via presynaptic $5-\mathrm{HT}_{1 \mathrm{~B}}$ heteroreceptors.

Concentrations as low as $0.3 \mu \mathrm{M}$ had significant effects on glutamatergic transmission, whereas the intrinsic properties of the targeted interneurons remained unaffected at this dosage. Notably, in a slice preparation of the inferior olive, the concen-
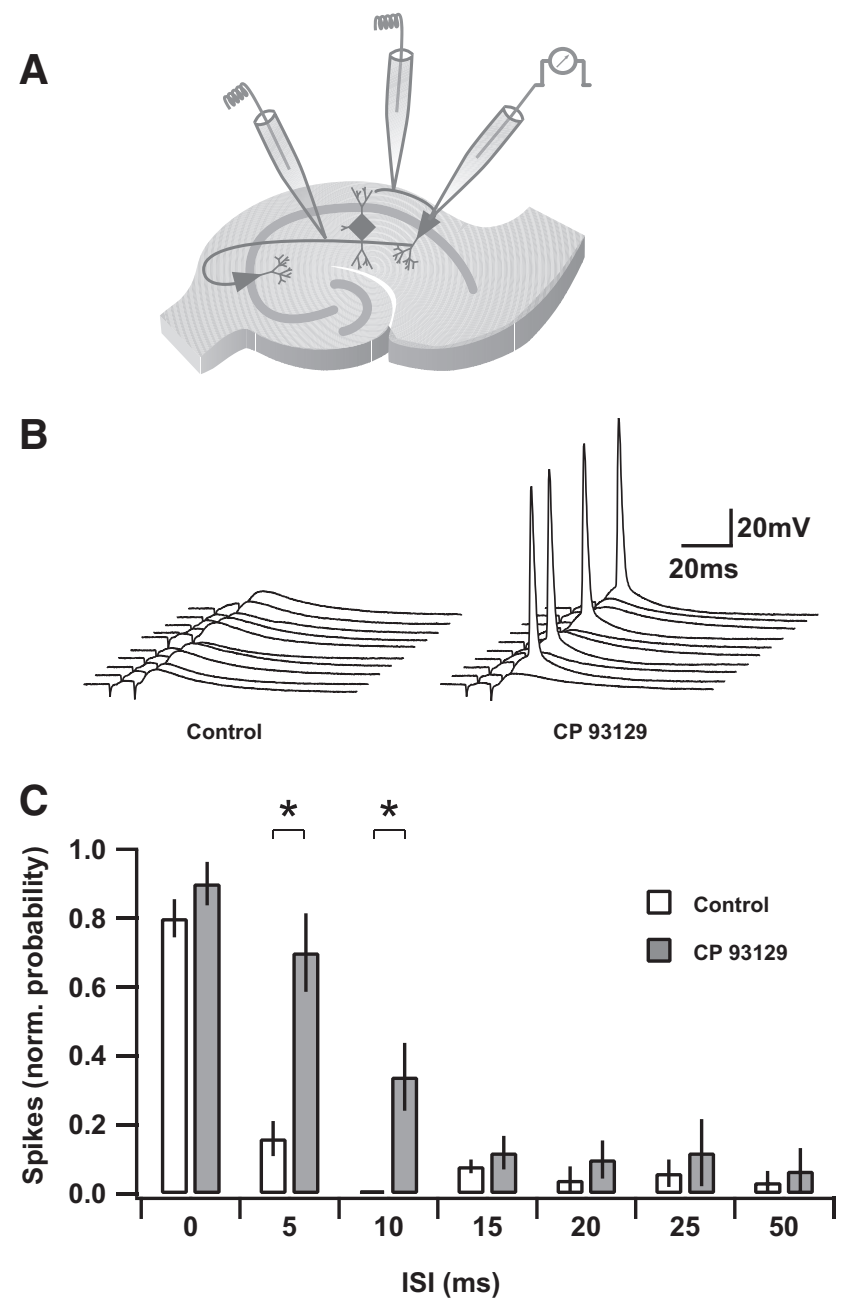

Figure 9. 5-HT increases the integration time window for spike timing in CA1 pyramidal cells. $\boldsymbol{A}$, Schematic of the recording configuration. $\boldsymbol{B}$, Example traces (single sweeps) of EPSPIPSP sequences stimulated in the alveus followed by EPSP-IPSP sequences elicited by Schaffercollateral stimulation in control and in $1 \mu \mathrm{M}$ (P93129 [interstimulus interval (ISI), $10 \mathrm{~ms}$ ]. C, Summary graph of the normalized spike probability at different interstimulus intervals $(n=5$; for 5 and $10 \mathrm{~ms}$ interstimulus intervals, ${ }^{*} p<0.05$, paired $t$ test).

tration of endogenously released serotonin, after stimulation of serotonergic brainstem nuclei, was estimated to be $\sim 0.5 \mu \mathrm{M}$ (Best and Regehr, 2008), i.e., a concentration range within which we could only detect significant effects on glutamate release from hippocampal CA1 pyramidal cells. Moreover, endogenously released serotonin induced by the application of fenfluramine was able to mimic the specific effect of exogenously applied serotonin. Our findings suggest that the reduction of glutamatergic transmission is a distinctive mechanism for the regulation of GABAergic action by serotonin, and the present effect of serotonin on glutamatergic excitation opposes that of the direct excitation of CCK-positive interneurons (McMahon and Kauer, 1997; Freund and Katona, 2007; Varga et al., 2009).

The depression of glutamatergic transmission onto interneurons by serotonin is most likely mediated by a presynaptic mechanism, as supported by several finding. First, 5-HT application led to an increased paired-pulse ratio. Second, analysis of the coefficient of variation applied to multi-afferent and minimal stimulation, as well as an increase of synaptic failures revealed a presynaptic locus of serotonin action. Finally, keeping the amount of released glutamate nominally constant by photolysis 
of caged glutamate, we could additionally show that 5-HT did not alter glutamate-evoked currents, whereas in the same interneurons, stimulus-evoked EPSCs were reduced in amplitude.

The receptor most likely mediating the presynaptic depression of glutamatergic transmission is of the $5-\mathrm{HT}_{1 \mathrm{~B}}$ receptor subtype. $5-\mathrm{HT}_{1 \mathrm{~B}}$ receptors are coupled to inhibitory G-proteins $\left(\mathrm{G}_{\mathrm{i}} /\right.$ $G_{o}$ ) and are thought to inhibit calcium channels via the $G_{o}$ subunit $\mathrm{G} \beta \gamma$. They act as autoreceptors or heteroreceptors at serotonergic and non-serotonergic neurons, respectively. In the hippocampus, activation of $5-\mathrm{HT}_{1 \mathrm{~B}}$ autoreceptors has been reported to inhibit 5-HT release, whereas $5-\mathrm{HT}_{1 \mathrm{~B}}$ heteroreceptors control acetylcholine release in the septohippocampal pathway and modulate glutamatergic transmission in the subiculum (for review, see Sari, 2004).

By means of glutamate uncaging and the consecutive focal activation of presynaptic pyramidal neurons, we provide evidence that the modulation of glutamate transmission on CCKpositive interneurons by serotonin is input specific. In agreement with the patterns of 5- $\mathrm{HT}_{1 \mathrm{~B}}$ receptor mRNA expression in the hippocampus (Voigt et al., 1991; Svenningsson et al., 2006), serotonergic depression of glutamate transmission was restricted to glutamatergic input derived from CA1 pyramidal cells. Furthermore, this set of experiments supports the suggested target cell specificity of serotonin action. Serotonin efficiently and selectively reduced glutamate release onto CCK-positive interneurons, i.e., Schaffer-collateral-associated interneurons and basket cells. Importantly, all CCK-positive interneurons were sensitive to the $5-\mathrm{HT}_{1 \mathrm{~B}}$ receptor agonist CP93129, when glutamate was uncaged on CA1 pyramidal cell bodies. This suggests that the observation of a few serotonin-insensitive CCK-positive cells (see above) can be attributed to insufficient activation of CA1 fibers by electrical stimulation. In contrast, PV-positive basket cells were never affected by serotonin or CP93129 application, in neither the experiments with electrical stimulation nor the experiments in which glutamate was uncaged on pyramidal cell bodies in area CA1. This finding is intriguing, because CCK-positive interneurons could be contacted specifically by a subclass of $5-\mathrm{HT}_{1 \mathrm{~B}}$-expressing $\mathrm{CA} 1$ pyramidal cells. Alternatively, within the same axonal plexus of a CA1 pyramidal cell, $5-\mathrm{HT}_{1 \mathrm{~B}}$ receptor expression could be restricted to terminals impinging onto CCKpositive interneurons. The latter explanation seems to be more likely, because there is no obvious mosaic-like expression of 5- $\mathrm{HT}_{1 \mathrm{~B}}$ receptor mRNA in the hippocampus (Voigt et al., 1991; Svenningsson et al., 2006). Additionally, there are examples in the literature in which a target-specific specialization of release properties within the same axonal arborization is described (Markram et al., 1998; Reyes et al., 1998) (for review, see Pelkey and McBain, 2007). The difference of serotonergic action between the two major classes of perisomatic inhibitory cells adds an additional argument to the concept that there is a functional dichotomy of perisomatic inhibition in the hippocampus (Freund and Katona, 2007).

Finally, we could show that the reduction of excitation of this inhibitory circuit is effectively transmitted onto the output elements, i.e., pyramidal cells in the hippocampal circuit. We observed a reduction of inhibition in CA1 pyramidal cells after application of 5-HT during alveus stimulation, implying an effect of serotonin on feedback inhibition. Corroborating this, we demonstrate an effective reduction in spike probability in serotoninsensitive interneurons after the application of the $5-\mathrm{HT}_{1 \mathrm{~B}}$ receptor agonist CP93129.

The reduction of feedback inhibition has functional implications for the integration time window of CA1 pyramidal cells. It has been shown that the narrow time window for spike generation in CA1 pyramidal cells is most likely provided by perisomatically targeting interneurons rather than by interneurons that impinge on the apical dendrites (Pouille and Scanziani, 2001). In line with this, altering the recruitment of perisomatically targeting CCK-positive basket cells during activation of $5-\mathrm{HT}_{1 \mathrm{~B}}$ receptors enabled CA1 pyramidal cells to integrate independent inputs over broader time windows. Together, this arrangement of serotonergic modulation of specific GABAergic action may constitute an important mechanism for subcortical control of hippocampal output.

\section{References}

Andrade R, Nicoll RA (1987) Pharmacologically distinct actions of serotonin on single pyramidal neurones of the rat hippocampus recorded in vitro. J Physiol 394:99-124.

Barnes NM, Sharp T (1999) A review of central 5-HT receptors and their function. Neuropharmacology 38:1083-1152.

Bendels MH, Beed P, Leibold C, Schmitz D, Johenning FW (2008) A novel control software that improves the experimental workflow of scanning photostimulation experiments. J Neurosci Methods 175:44-57.

Best AR, Regehr WG (2008) Serotonin evokes endocannabinoid release and retrogradely suppresses excitatory synapses. J Neurosci 28:6508-6515.

Boeijinga PH, Boddeke HW (1996) Activation of 5-HT1B receptors suppresses low but not high frequency synaptic transmission in the rat subicular cortex in vitro. Brain Res 721:59-65.

Cobb SR, Buhl EH, Halasy K, Paulsen O, Somogyi P (1995) Synchronization of neuronal activity in hippocampus by individual GABAergic interneurons. Nature 378:75-78.

Colino A, Halliwell JV (1987) Differential modulation of three separate K-conductances in hippocampal CAl neurons by serotonin. Nature 328:73-77.

Duman RS, Heninger GR, Nestler EJ (1997) A molecular and cellular theory of depression. Arch Gen Psychiatry 54:597-606.

Faber DS, Korn H (1991) Applicability of the coefficient of variation method for analyzing synaptic plasticity. Biophys J 60:1288-1294.

Fink KB, Göthert M (2007) 5-HT receptor regulation of neurotransmitter release. Pharmacol Rev 59:360-417.

Földy C, Lee SY, Szabadics J, Neu A, Soltesz I (2007) Cell type-specific gating of perisomatic inhibition by cholecystokinin. Nat Neurosci 10: $1128-1130$.

Freund TF, Katona I (2007) Perisomatic inhibition. Neuron 56:33-42.

Freund TF, Gulyás AI, Acsády L, Görcs T, Tóth K (1990) Serotonergic control of the hippocampus via local inhibitory interneurons. Proc Natl Acad Sci U S A 87:8501-8505.

Glickfeld LL, Scanziani M (2006) Distinct timing in the activity of cannabinoid-sensitive and cannabinoid-insensitive basket cells. Nat Neurosci 9:807-815.

Krishnan V, Nestler EJ (2008) The molecular neurobiology of depression. Nature 455:894-902.

Markram H, Wang Y, Tsodyks M (1998) Differential signaling via the same axon of neocortical pyramidal neurons. Proc Natl Acad Sci U S A 95:5323-5328.

McBain CJ, Fisahn A (2001) Interneurons unbound. Nat Rev Neurosci 2:11-23.

McMahon LL, Kauer JA (1997) Hippocampal interneurons are excited via serotonin-gated ion channels. J Neurophysiol 78:2493-2502.

Miles R, Tóth K, Gulyás AI, Hájos N, Freund TF (1996) Differences between somatic and dendritic inhibition in the hippocampus. Neuron 16:815-823.

Mlinar B, Falsini C, Corradetti R (2003) Pharmacological characterization of 5-HT(1B) receptor-mediated inhibition of local excitatory synaptic transmission in the CA1 region of rat hippocampus. Br J Pharmacol 138:71-80

Neu A, Földy C, Soltesz I (2007) Postsynaptic origin of CB1-dependent tonic inhibition of GABA release at cholecystokinin-positive basket cell to pyramidal cell synapses in the CA1 region of the rat hippocampus. J Physiol 578:233-247.

Pawelzik H, Hughes DI, Thomson AM (2002) Physiological and morphological diversity of immunocytochemically defined parvalbumin- and 
cholecystokinin-positive interneurones in CA1 of the adult rat hippocampus. J Comp Neurol 443:346-367.

Pelkey KA, McBain CJ (2007) Differential regulation at functionally divergent release sites along a common axon. Curr Opin Neurobiol 17:366-373.

Pouille F, Scanziani M (2001) Enforcement of temporal fidelity in pyramidal cells by somatic feed-forward inhibition. Science 293:1159-1163.

Ressler KJ, Nemeroff CB (2000) Role of serotonergic and noradrenergic systems in the pathophysiology of depression and anxiety disorders. Depress Anxiety 12[Suppl 1]:2-19.

Reyes A, Lujan R, Rozov A, Burnashev N, Somogyi P, Sakman B (1998) Target-cell-specific facilitation and depression in neocortical circuits. Nat Neurosci 4:279-285.

Sari Y (2004) Serotonin1B receptors: from protein to physiological function and behavior. Neurosci Biobehav Rev 28:565-582.

Schmitz D, Empson RM, Heinemann U (1995) Serotonin reduces inhibition via 5-HT1A receptors in area CA1 of rat hippocampal slices in vitro. J Neurosci 15:7217-7225.

Schmitz D, Gloveli T, Empson RM, Heinemann U (1999) Potent depression of stimulus evoked field potential responses in the medial entorhinal cortex by serotonin. Br J Pharmacol 128:248-254.
Schmitz D, Mellor J, Breustedt J, Nicoll RA (2003) Presynaptic kainate receptors impart an associative property to hippocampal mossy fiber longterm potentiation. Nat Neurosci 6:1058-1063.

Svenningsson P, Chergui K, Rachleff I, Flajolet M, Zhang X, El Yacoubi M, Vaugeois JM, Nomikos GG, Greengard P (2006) Alterations in 5-HT1B receptor function by 11 in depression-like states. Science 311:77-80.

Torres GE, Chaput Y, Andrade R (1995) Cyclic AMP and protein kinase A mediate 5-hydroxytryptamine type 4 receptor regulation of calciumactivated potassium current in adult hippocampal neurons. Mol Pharmacol 47:191-197.

Torres GE, Arfken CL, Andrade R (1996) 5-Hydroxytryptamine4 receptors reduce afterhyperpolarization in hippocampus by inhibiting calciuminduced calcium release. Mol Pharmacol 50:1316-1322.

Varga V, Losonczy A, Zemelman BV, Borhegyi Z, Nyiri G, Domonkos A, Hangya B, Holderith N, Magee JC, Freund TF (2009) Fast synaptic subcortical control of hippocampal circuits. Science 326:449-453.

Voigt MM, Laurie DJ, Seeburg PH, Bach A (1991) Molecular cloning and characterization of a rat brain cDNA encoding a 5-hydroxytryptamine1B receptor. EMBO J 10:4017-4023.

Zucker RS, Regehr WG (2002) Short-term synaptic plasticity. Annu Rev Physiol 64:355-405. 